\title{
Adaptability in buildings - housing context - literature review
}

\author{
Roman Milwicz ${ }^{1, *}$, Jerzy Pasławski ${ }^{1}$ \\ ${ }^{1}$ PUT, Civil ad Environmental Engineering, Piotrowo 5, 60-101 Poznań, Poland
}

\begin{abstract}
Dynamic development of technology that influences social lifestyles has great impact over the way of understanding the house and thus the way of designing this special space. The buildings have to fulfill the sustainability conditions and a lot has been done to decrease impact of building on environment. Among many ways one is the flexibility, which strongly influences economical, social and environmental aspects. Authors tried to collect most significant papers and monographs that treat the flexibility and adaptability and thus show its importance in civil engineering especially in housing sector. In the conclusions Authors shears the ideas of investigations within housing adaptability filed.
\end{abstract}

\section{Introduction}

The building is not a static object; it remains unfinished until the day of its demolition. This phenomenon had been known since prehistoric times. The buildings is constructed to be useful but needs are not permanent, they are changing in various time horizon from phases of a day, seasons, years. Sometimes need change with time in other case with the change of user or development of technology. People always tried to use the building, as long as possible that is why a lot of ways for adaptation has been introduced during the history of human beings. Thoughts related to adaptability and the time of they appearance is presented in the fig.1. Contemporary civil engineering and architecture have important role to develop, evaluate and disseminate the knowledge connected with adaptability with indeed plays considerable role in sustainable development. Thus the authors standing at the threshold of investigations concerning adaptability in single family housing, would like to present the literature review and indicate the milestones within the field of study.

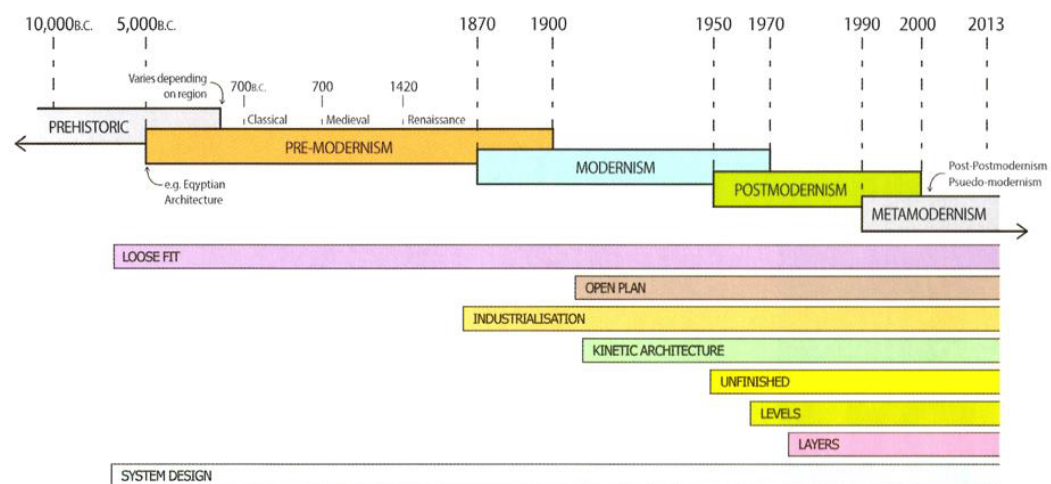

Fig. 1. Development of adaptability [1]

*Corresponding author: roman.milwicz@put.poznan.pl 


\section{Historical overview}

At the beginning people look for shelter in the natural formations which were mostly caves, because of nomadic lifestyle they had to adapt and create the shelter themselves - inventing primitive huts and tents. It was discovered quite early that it is more practical to create bigger space in advance than rebuild the hideaway. This way of adaptability was major for long time up to the Industrial Revolution. Bigger precision and possibility of mass production open the way to build cheaper and faster. First well known building was Cristal Palace erected in 1851 from precast elements. Bold plans of Le Corbusier and his rules gave new quality of buildings. His open plan [2] presented on domino house in 1914 allowed big adaptable performance. It split the bearing structure and other elements. Thank to this solution the space can be created freely by the user. Paralelly the lack of space force designers to create the building that can change quickly and repeatedly the space by e.g. moving portions, such houses are called convertible [3]. Recent 50 years bring a lot of knowledge, which is presented, in next paragraph.

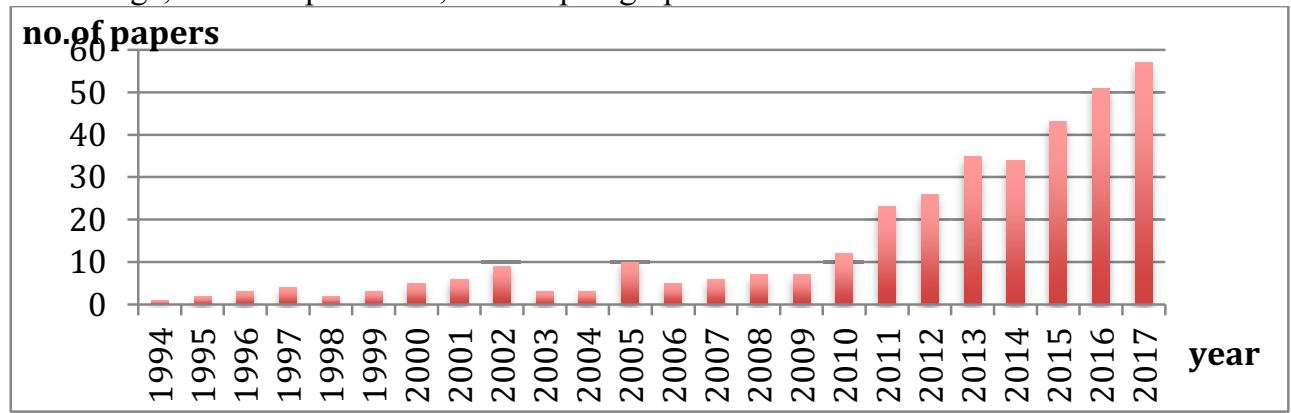

Fig. 2. Development of adaptability [4]

\section{Designing for adaptability - general review}

Adaptability becomes more and more recognisable term; one can observe substantial development in number of publication touching the adaptability in building context fig. 2 . "If the building does not support (technologically and technically) change and reuse you have only the illusion of sustainable construction [5] - this sentence shows how important is the adaptability in sustainable development. Some attributes of adaptability are as follows: in the housing heating context the most important seems to be the ability to change volume, function or performance [6], ease of response to the changed conditions [7] presence of less common but more dramatic changes [8]. Adaptability of buildings means to remain ready for change in order to respond the needs or reduce the mismatch [9]. Schmidt III and Austin had done great work; Authors would like to show the strands of designing for adaptability (fig.3.), which explain the progress of adaptability in architecture. [1] The diversity of adaptation methods may give a blurred image of what this term means and how to implement this feature, thus the framework of main types is presented in fig.4. 


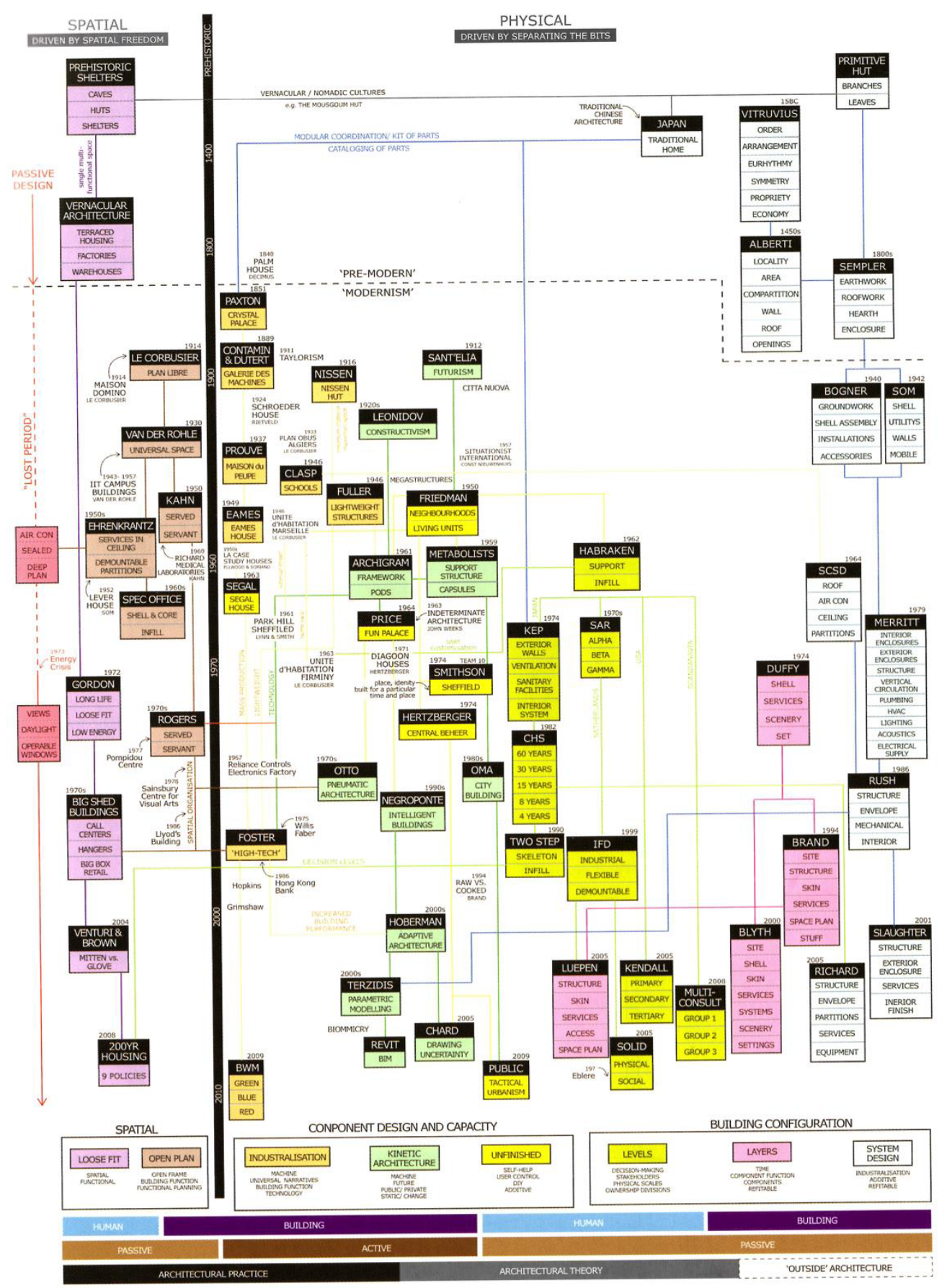

Fig. 3. Strands of designing for adaptability [1]

The implementation of adaptability needs the understanding the components of the building their cooperation and lifespan. The building decomposition is crucial in adaptable buildings the idea of shearing layers was introduced by Duffy and Henney in 1989 and 
developed by Brand in 1994 and later by Blyth in 2000. The building element are subdivided into sharing layers with different lifespan expectancy (fig.5.):

- Site: the land where the building is erected

- Structure: load bearing elements e.g. foundations, beams columns walls

- Skin: protection from external factors: cladding - walls and roof

- Service: Working guts of the building e.g. electrical, plumbing, HVAC

- Space plan: interior layout

- Stuff: furniture [10]

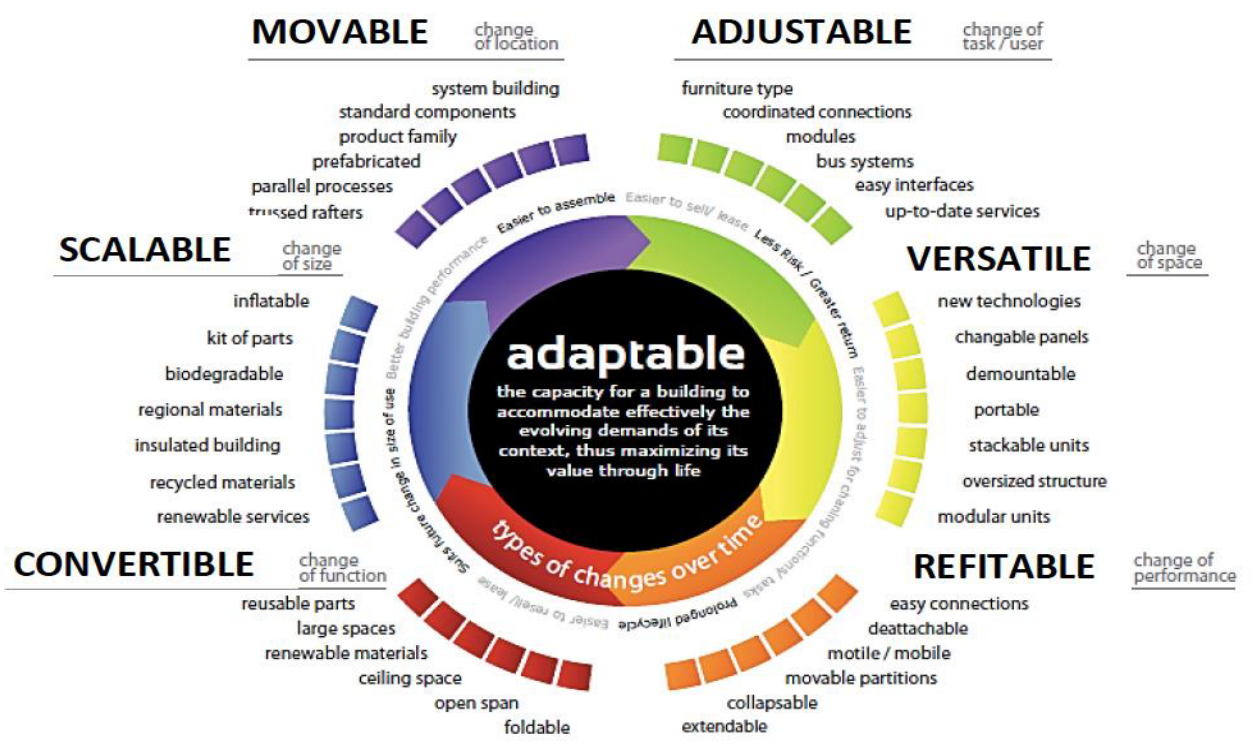

Fig. 4. Adaptable framework [11]

The most important lesson learned form this division is that each sharing layer has different life expectancy and needs to be replace or repair during the life time in various time thus it is essential to design building in such a way to make this process easy and cost effective; the simplest way is not to mix functions of single element among different layers. In other words The 'theory of layers allows the components of the building to be broken down into packages of same or similar life expectance so that a whole package might be conveniently deconstructed from the building for replacement, recycling and/or reuse elsewhere' [12].

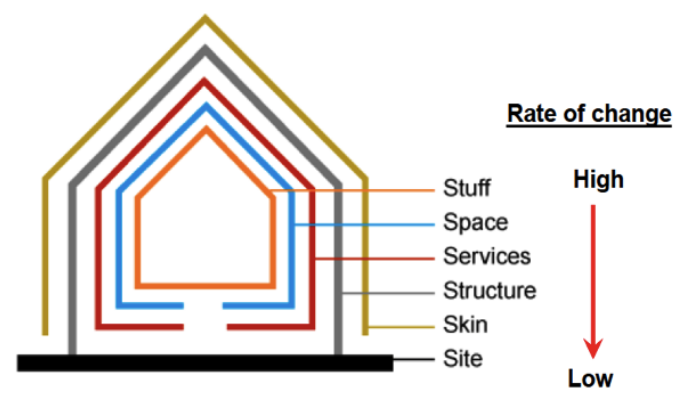

\begin{tabular}{ll}
\hline Shearing layer & Life expectancy \\
\hline Site & Eternal \\
\hline Structure & $30-300$ years \\
\hline Skin & $20+$ years \\
\hline Services & $7-20$ years \\
\hline Space plan & 3 years \\
\hline Stuff & Under 3 years \\
\hline
\end{tabular}


Fig.5. Sharing layers with life expectancies.

There is the connection between sharing layers and adaption types presented in fig.4. One can observe the difference in frequency of changes among different layers. More frequent changes are with little importance and take place in interior and can be done by user, on the other hand bigger changes are less frequent and involve designers within the process mainly because they interfere in external and load bearing components. Next step of investigations might be adaptive reuse potential introduced by Langstom [13]. This is the tool for measuring the potential of existing buildings to adopt for future potential change. Introduced model [14] ranks the potential of adaptation and can be implemented in all types of buildings all over the world. The ARP model take into account the age predicted lifespan and rate of obsolesce. The better score the higher potential for success.

Table 1. The influence of shearing layers in different adaptable strategies.

\begin{tabular}{|l|l|l|c|c|c|c|c|c|}
\hline Strategy & \multirow{2}{*}{ B-E Scale } & \multirow{2}{*}{$\begin{array}{c}\text { Speed of } \\
\text { change }\end{array}$} & & \multicolumn{7}{|c|}{ Shearing layers } \\
\cline { 6 - 11 } & & & Stuff & Space & Services & Skin & Structure & Site \\
\hline Adjustable & Components & Daily/monthly & $\bullet$ & & & & & \\
\hline Versatile & Components & Daily/monthly & $\bullet$ & $\bullet$ & & & & \\
\hline Refitable & Components & 7 years & & $\bullet$ & $\bullet$ & $\bullet$ & & \\
\hline Convertible & Building & 15 years & & $\bullet$ & $\bullet$ & $\bullet$ & & \\
\hline Scalable & Building & 15 years & & $\bullet$ & $\bullet$ & $\bullet$ & $\bullet$ & \\
\hline Moveable & Building & 30 years & & & & & $\bullet$ & $\bullet$ \\
\hline
\end{tabular}

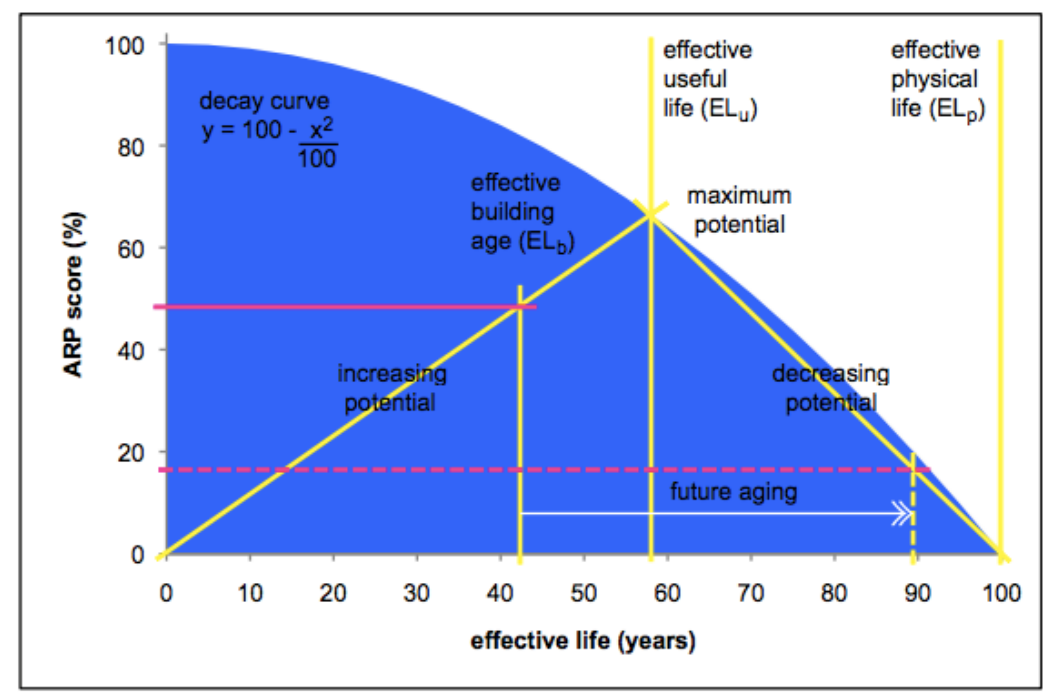

$\operatorname{ARP}$ (increasing) $=\frac{100-\frac{E L_{u}{ }^{2}}{100}}{E L_{u}} \cdot E L_{b} \quad A R P$ (decreasing) $=\frac{100-\frac{E L_{u}{ }^{2}}{100}}{100-E L_{u}} \cdot\left(100-E L_{b}\right)$

Fig.5. Adaptive reuse potential model [13] 


\section{Adaptability in housing}

The last topic that Authors would like to touch is the adaptability in housing sector. The main reason is that the house or flat is really complex type of building mainly because of diversity of activities. Estaji neatly describes the phenomenon [15]. In his works he describes the concept of "Ideal House" that covers all human needs. But the problem lays in rapid change of needs. The paper presents complexity of the house task, with have to answer human needs, on the one hand 12 phases of life (long time horizon -years and decades) fig.6., on the other hand type of activity (short time horizon - hours and days) fig.7. What is important and have been mentioned by Milwicz [16] not only needs are changing but also financial possibilities fig. Such relationship makes designing problem even more complicated.

\begin{tabular}{|c|c|c|}
\hline \multicolumn{3}{|c|}{$\begin{array}{c}\text { Twelve Phases of Human } \\
\text { Development }\end{array}$} \\
\hline 岕 & Name of phase & Ages \\
\hline 1 & Pre-natal & $-9 \mathrm{mo} .-0$ \\
\hline 2 & Breast dependence & 0-6 mo. \\
\hline 3 & Infant & 7-15 mo. \\
\hline 4 & Toddler & $16-29 \mathrm{mo}$ \\
\hline 5 & Preschool & $30 m o .-5 y$ \\
\hline 6 & School age & $6-12$ \\
\hline 7 & Adolescence & $13-18$ \\
\hline 8 & Young adulthood & $19-25$ \\
\hline 9 & Middle adulthood & $26-40$ \\
\hline 10 & Real adulthood & $41-60$ \\
\hline 11 & Early old age & 61.75 \\
\hline 12 & Old age & $76-100$ \\
\hline
\end{tabular}

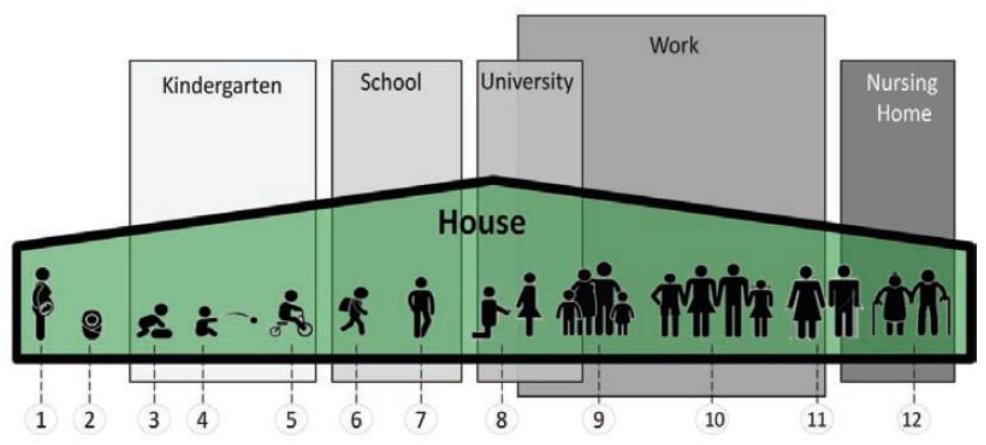

Fig.6. Comparison of the coverage of human development phases by different buildings [15]

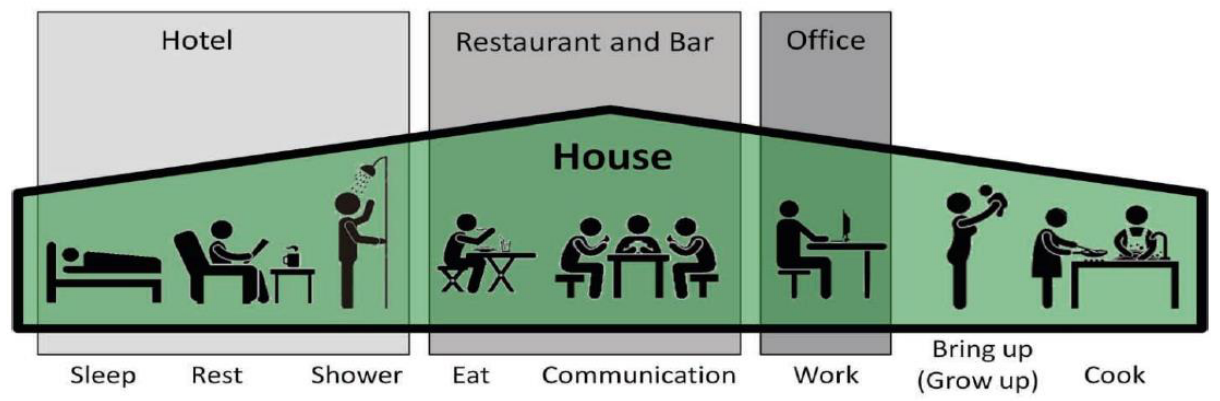

Fig.7. Human activities [15]

In spite of great importance of adaptability in housing sector only a few countries conduct the investigation and introduced the appropriate housing programme namely in UK by Habraken [16] and Schneider, T., \& Till, J. [17], Germany by Huber [18] and Schittich [19] and in Japan [20] in this country the project has started in ' 70 and results influenced the construction codes extending life cycle of building. 


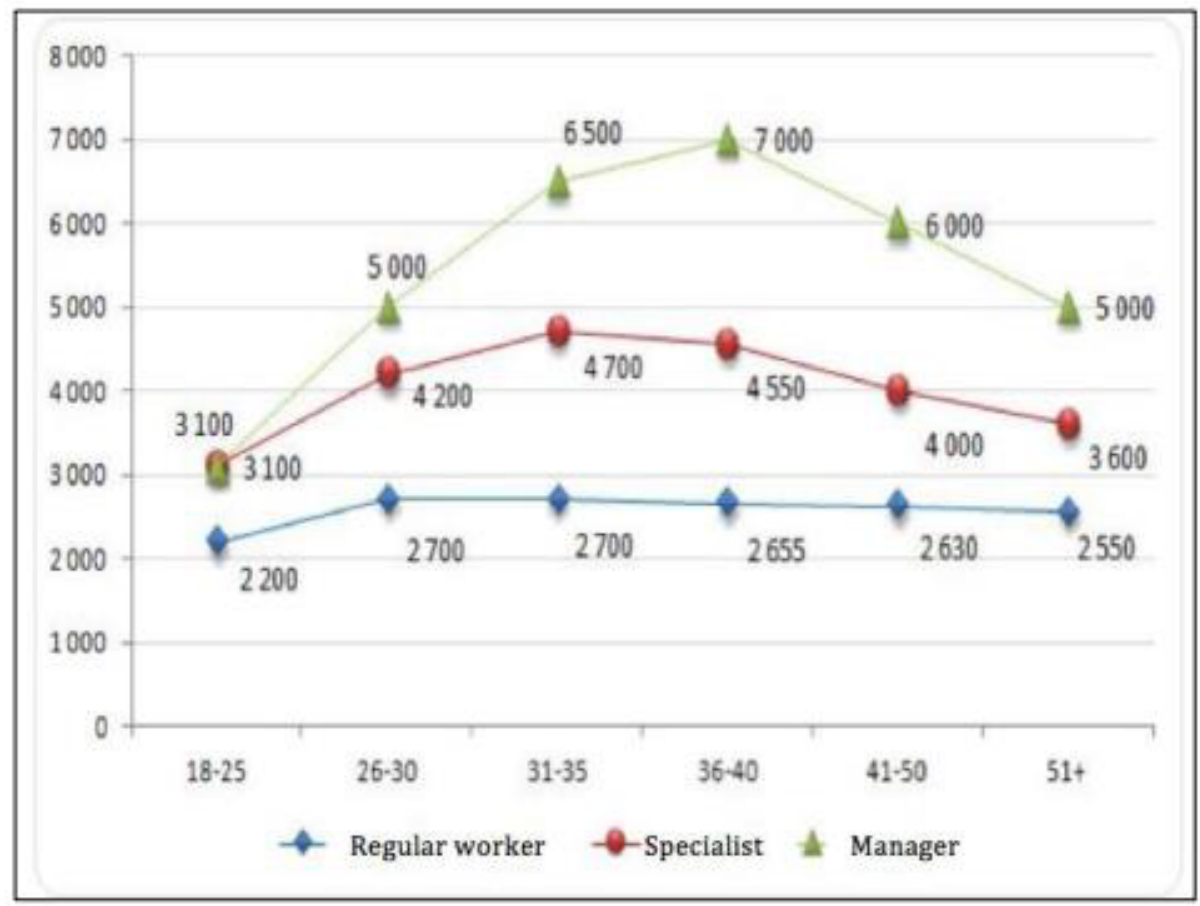

Fig. 8. Salary [PLN] vs. age of worker [years]

\section{Summary}

Lively interest in adaptation issues will surely will give fruits and help to construct more sustainable buildings. The investigations shows that it is not a single field involved in the case, it a combination o actions such as architecture, civil engineering, environmental engineering, psychology, sociology and many others. The investigations also give tangible results in the field or restoration the example could be paper of Jensen [21]. Nowadays construction reached the satisfying level of energy efficiency and material optimization, now it is time to make flexible buildings than can easily adapt to more and more rapid changes.

From the literature reader can derive following conclusions:

1. There is high need to implement adaptability in buildings

2. Adaptability can be divided into passive and active

3. Main factor of adaptability are: height of rooms, separate construction, avoidance of bearing walls inside the plan, modularity.

Authors see the need to investigate the concept in single-family housing. The concept is to check what kind of adaptability can bring bigger profits. They intend to compare regular house with modular adjustable (active adaptability) and house with the possibility to adapt the attic for future needs (passive adaptability). The special place is dedicated movable modules that can be added or disconnected to the building in any time. Next article will explain the concept and show the possibilities of applying. According to Authors the concept can increase the housing affordability. 


\section{References}

1. R.Schmidt III, S. Austin, Adaptable Architecture, Theory and practice, Routledge Taylor \& Francis Group, NY (2016)

2. Le Corbusier, Vers une architecture,(1923)

3. A. Friedman, The adaptable house: Designing homes for change. McGraw-Hill. New York (2002)

4. Science direct statistics (access 3.07.2018)

5. W. Croxton, Disassembly and Deconstruction, Architectural Record, (2003)

6. J. Douglas, Building adaptation. 2nd ed. Great Britain, Elsevier Ltd. (2006)

7. R. Kronenburg, Flexibile Architecture that responds to change. Laurence King Publishers. London (2007)

8. A. Leaman, B. Bordass, Flexibility and Adaptability. In designing better buildings, Macmillan, S., Spon Press. 145-156, (2004)

9. A. Friedman, The adaptable house: Designing homes for change. McGraw-Hill. New York (2002)

10. S. Brand, How Buildings Learn: What happens after they're Built, Penguin, New York, (1994)

11. K., Beadle, A. Gibb, S. Austin, A. Fuster, P. Madden, Adaptable futures: setting the agenda in Proceedings of the 1 st I3CON International Conference, Loughborough University, Loughborough, UK, 14-16 May. (2008),

12. P. Crowther, Developing an inclusive model for design for deconstruction, A.R. CHINI, ed. In: Deconstruction and Materials Reuse: Technology, Economic, and Policy, 6th April 2001, CIB, International Council for Research and Innovation in Building Construction, Wellington, New Zealand, (2001)

13. C. Langston, F.K.W., Wong, C.M. Eddie, And H.L., Shen, Strategic assessment of building adaptive reuse opportunities in Hong Kong. Building and Environment, 43(10), 1709-1718, (2008)

14. C. Langston, On archetypes and building adaptive reuse, Proceedings of 17th Pacific Rim Real Estate Society (PRRES) Conference, Gold Coast, Australia. 16th -19 th (2011)

15. H. Estaji, A Review of Flexibility and Adaptability in Housing Design Internat. Jour. of Contemp. Arch. "The New ARCH“"Vol. 4, No. 2, (2017)

16. R. Milwicz, P. Nowotarski, Influence of multiphase flexible timber frame house construction on housing affordability, Proc. Eng. 122,158 - 165, (2015)

17. N.J. Habraken, Design For Flexibility. Building Research \& Information, 36 (3), 290-296. (2008)

18. T. Schneider, J. Till, Flexible Housing. Oxford, United Kingdom: Architectural Press, (2007)

19. A. Huber, New Approaches to Housing for the Second Half of Life, Birkhäuser, Berlin, (2008)

20. Ch. Schittich, In Detail: Housing for People of All Ages, Birkhäuser, Berlin, (2007)

21. K. Minami, The efforts to develop longer life housing with adaptability in Japan Energy Procedia (1996)

22. P.A. Jensen, E. Masles, J. Brinkø, Ch. Thuesen, 10 questions concerning sustainable building renovation, Building and Environment 143,130-137, (2018) 